\title{
Unexpected Precipitation Observed during Arsenic Removal from Water via Sorbent Modified with a Mixed Oxidation State Manganese
}

\author{
Andrey E. Krauklis ${ }^{1,2 *}$
}

${ }^{1}$ Department of Mechanical and Industrial Engineering, Norwegian University of Science and Technology, 7491 Trondheim, Norway

${ }^{2}$ Department of Environmental Science, University of Latvia, Riga, LV-1004, Latvia

*Corresponding author: Andrey E. Krauklis, Department of Mechanical and Industrial Engineering, Norwegian University of Science and Technology, 7491 Trondheim, Norway, Tel: +37126810288; E-mail: andrejs.krauklis@ntnu.no

Received date: Aug 04, 2018; Accepted date: Aug 22, 2018; Published date: Aug 31, 2018

Citation: Krauklis AE (2018) Unexpected Precipitation Observed during Arsenic Removal from Water via Sorbent Modified with a Mixed Oxidation State Manganese. Int J Appl Sci Res Rev. Vol.5 No.3:11.

Copyright: @ 2018 Krauklis AE. This is an open-access article distributed under the terms of the Creative Commons Attribution License, which permits unrestricted use, distribution, and reproduction in any medium, provided the original author and source are credited.

\section{Abstract}

Drinking water contamination with $\mathrm{As}(\mathrm{V})$ is a crucial problem for millions of people dependent on groundwater resources in some regions of the world. Accumulation of arsenic compounds in the body by using such water poses serious health risks. Among many types of materials, Mn-modified sorbents are used for water treatment and arsenic removal. In this short communication, a newly observed phenomenon is reported, being an unexpected precipitation process occurring during the $\mathrm{As}(\mathrm{V})$ sorption from an aqueous solution via $\mathrm{Mn}$-modified clinoptilolite. The quantity of formed precipitates was observed to increase with the initial concentration of $\mathrm{As}(\mathrm{V})$ present in water. While this short communication is intended only to report a novel observation, some implications can be expected. Additional studies are required to understand the underlying mechanism and implications of such precipitation during the water treatment process, raising questions on limitations of the use of such sorbents. While it is not completely certain, limited experimental evidence indicates that precipitates are formed by interaction of $\mathrm{Mn}_{8} \mathrm{O}_{10} \mathrm{Cl}_{3}$ (mixed oxidation state $\mathrm{Mn}$ ) and As(V), and exist in the form of hydrates. The precipitates are unstable in air at room temperature and moderate humidity, and degrade shortly thereafter outside of water solution.

Keywords: Water treatment; Precipitation; As(V); Arsenic removal; Sorption; Manganese

\section{Introduction}

Groundwater contamination with $\mathrm{As}(\mathrm{V})$ compounds is a problem for millions of people as these resources are crucial for use as drinking water [1-3]. Accumulation of arsenic compounds in the body due to use of such water poses significant health risks and may lead to arsenicosis [3]. Arsenic contamination is both natural and due to human activity. Weathering of rocks and minerals is a typical example of a natural process, while metal waste, fertilizers, fossil fuel combustion and pesticides are due to agricultural and industrial activities [4-6].

Sorption is considered as one of the most feasible water treatment techniques in arsenic removal because of its relatively low costs [7-10]. Zeolites are highly crystalline, microporous and hydrated aluminosilicate minerals, which contain alkali or alkaline cations. Clinoptilolite is a high $\mathrm{SiO}_{2}$ content heulandite group mineral and often is the main component of natural zeolites. Unmodified zeolites usually have a low affinity for arsenic due to an electrostatic repulsion between the anions and the framework of the zeolite. In such cases, surface modification, i.e. via manganese compounds, is a possible route for substantially improving oxyanion sorption [9].

Manganese compounds are used for modification of sorbents for $A s(V)$ removal from water $[11,12]$. Clinoptilolite modification with manganese oxides significantly enhances sorption capacity of $\mathrm{As}(\mathrm{V})$ compared to an unmodified clinoptilolite [11-13]. $\mathrm{Mn}_{8} \mathrm{O}_{10} \mathrm{Cl}_{3}$-modification improves $\mathrm{As}(\mathrm{V})$ sorption capacities of zeolites [11,12]. As(V) has affinity towards crystalline $\mathrm{Mn}_{8} \mathrm{O}_{10} \mathrm{Cl}_{3}$ [11]. Thus, the newly observed phenomenon is important to understand and consider when Mn-modified sorbents are to be used in practice.

During sorption experiments of a mixed oxidation state $\mathrm{Mn}$ modified natural zeolites (clinoptilolite) for removal of $\mathrm{As}(\mathrm{V})$ in water, an unexpected precipitation was observed, in result of which translucent greyish flakes were formed and sedimented.

The aim of this short communication is to report the newly observed phenomenon, which is of significance for the removal of arsenic compounds from water using manganesemodified sorbents. This phenomenon has not been reported before to the best knowledge of the author. 


\section{Materials}

Clinoptilolite-rich (clinoptilolitic content 86-94\%) natural zeolite from Slovakian deposit Nižný Hrabovec was modified with a mixed oxidation state manganese compound $\mathrm{Mn}_{8} \mathrm{O}_{10} \mathrm{Cl}_{3}$ and was then used as a sorbent for arsenic removal. The specific weight of the unmodified material was 2200-2440 $\mathrm{kg} / \mathrm{m}^{3}$ and porosity was $24-32 \%$. The material also contains cristobalite, clay mica, plagioclase, rutile, quartz. Size of particles was 1-2.5 mm [12,14].

The modification method of natural zeolites with a mixed oxidation state manganese oxide used in this communication is also reported in two other works $[11,12]$. Conditions of the modification are also consistent with that of $\mathrm{Mn}_{8} \mathrm{O}_{10} \mathrm{Cl}_{3}$ synthesis described by G. Buisson [15]. $100 \mathrm{~g}$ of raw material were weighted and dried in air atmosphere in the oven for $1 \mathrm{~h}$ at $70^{\circ} \mathrm{C}$. $2.5 \mathrm{M} \mathrm{MnCl}_{2}$ and $10 \mathrm{M} \mathrm{NaOH}$ solutions were prepared. While mixing, $100 \mathrm{~mL}$ of $2.5 \mathrm{M} \mathrm{MnCl}_{2}$ solution were added to the zeolite. Then, $1 \mathrm{~mL}$ of $10 \mathrm{M} \mathrm{NaOH}$ solution was added. The mixture was stirred and then aged for $24 \mathrm{~h}$. After, it was placed in the oven for $3 \mathrm{~h}$ at $150^{\circ} \mathrm{C}$, resulting in the densified modified zeolite mass. This mass was then placed in the muffle furnace and was held there for $5 \mathrm{~h}$ in air atmosphere at $550^{\circ} \mathrm{C}$. After, it was taken out and cooled down in air at room temperature. After cooling, modified zeolite was washed with $300 \mathrm{~mL}$ of DI water. Material was dried in air for 1 $h$ at room temperature, and further dried in the oven Gallenkamp Plus II (London, UK) for $4 \mathrm{~h}$ at $60^{\circ} \mathrm{C}$. Modified material had $\mathrm{Mn}$ content of $8.40 \pm 0.51 \mathrm{w} \%$.

Unmodified natural clinoptilolite is able to sorb up to $0.36 \pm$ $0.02 \mathrm{mg} / \mathrm{g}$ of $\mathrm{As}(\mathrm{V})$. Mn-modification increases sorbed amount of $\mathrm{As}(\mathrm{V})$ up to 13.7 times (4.92 $\pm 0.30 \mathrm{mg} / \mathrm{g}$ ) [11]. The amount of $\mathrm{Mn}$ compound was the same in all the studied samples.

All compounds used during this work were of analytical grade ( $\geq 98 \%)$. Sodium hydroxide was obtained from SigmaAldrich (Riedel-de Haën, Germany). Manganese(II) chloride tetrahydrate was obtained from Firma Chempur (Piekary Śląskie, Poland). All aqueous solutions were prepared using high purity deionized water $(10-15 \mathrm{M} \Omega \cdot \mathrm{cm})$, produced via water purification system Millipore Elix 3 (Billerica, USA). Arsenate solutions were prepared using disodium hydrogenarsenate heptahydrate $\mathrm{Na}_{2} \mathrm{HAsO}_{4} \cdot 7 \mathrm{H}_{2} \mathrm{O}$ obtained from Alfa Aesar (Haverhill, USA).

\section{Experimental}

\section{SEM, EDX and XRD}

Scanning electron microscopy (SEM) and Energy-dispersive X-ray spectroscopy (EDX) were performed using PhenomWorld Phenom ProX (Waltham, USA) in backscattered electron regime with working voltage of $15 \mathrm{kV}$. Studied material was covered with a thin layer of gold in order to prevent charging due to electron beam. Gold sputtering was performed using Quorum Technologies Emitech K550X (Laughton, UK).
X-ray diffraction (XRD) was performed using instrument Bruker D8 Advance (Billerica, USA). Radiation source: $\mathrm{Cu} K \alpha, \lambda$ $=1.54180 \AA$; Anode voltage $40 \mathrm{kV}$; Anode current $40 \mathrm{~mA} ; \mathrm{K} \beta$ filter $0.02 \mathrm{~mm}$ thick nickel foil; slits: divergence $0.6 \mathrm{~mm}$, antiscattering $8.0 \mathrm{~mm}$; scanning range: $2 \theta=3-55^{\circ}$, step $0.02^{\circ}$, step time $0.5 \mathrm{~s}$; energy-dispersive one-dimensional detector Lynx Eye.

A combination of SEM, EDX and XRD allowed to ensure that the zeolite was successfully modified with a crystalline mixed oxidation state manganese oxide-chloride $\mathrm{Mn}_{8} \mathrm{O}_{10} \mathrm{Cl}_{3}$. The details of these results are reported in another work [11].

\section{Arsenic removal experiments}

Arsenic removal or sorption experiments were conducted using a batch system. $\mathrm{Na}_{2} \mathrm{HAsO}_{4} \cdot 7 \mathrm{H}_{2} \mathrm{O}$ was used for preparation of arsenic solutions of various concentrations (5, 10, 25, 50, 100, 200 and $300 \mathrm{mg} / \mathrm{L}) .0 .5000 \pm 0.0001 \mathrm{~g}$ sorbent was weighed in each glass vessel using analytical scales Kern ALJ 220-4 (Balingen, Germany) and 30.00 $\pm 0.05 \mathrm{~mL} \mathrm{As}(\mathrm{V})$ solution was then added to every vessel. Vessels were shaken for $24 \mathrm{~h}$ at room temperature $\left(23 \pm 1^{\circ} \mathrm{C}\right)$ at $150 \mathrm{rpm}$ using orbital shaker Biosan Multi-functional Orbital Shaker PSU-20i (Riga, Latvia) to ensure sorption equilibrium was achieved.

\section{Results and Discussion}

EDX analysis of the modified sorbent indicated that it contained $8.40 \pm 0.51 \mathrm{w} \%$ of the Mn. EDX of the initial zeolite showed it contained no traceable amounts of $\mathrm{Mn}$.

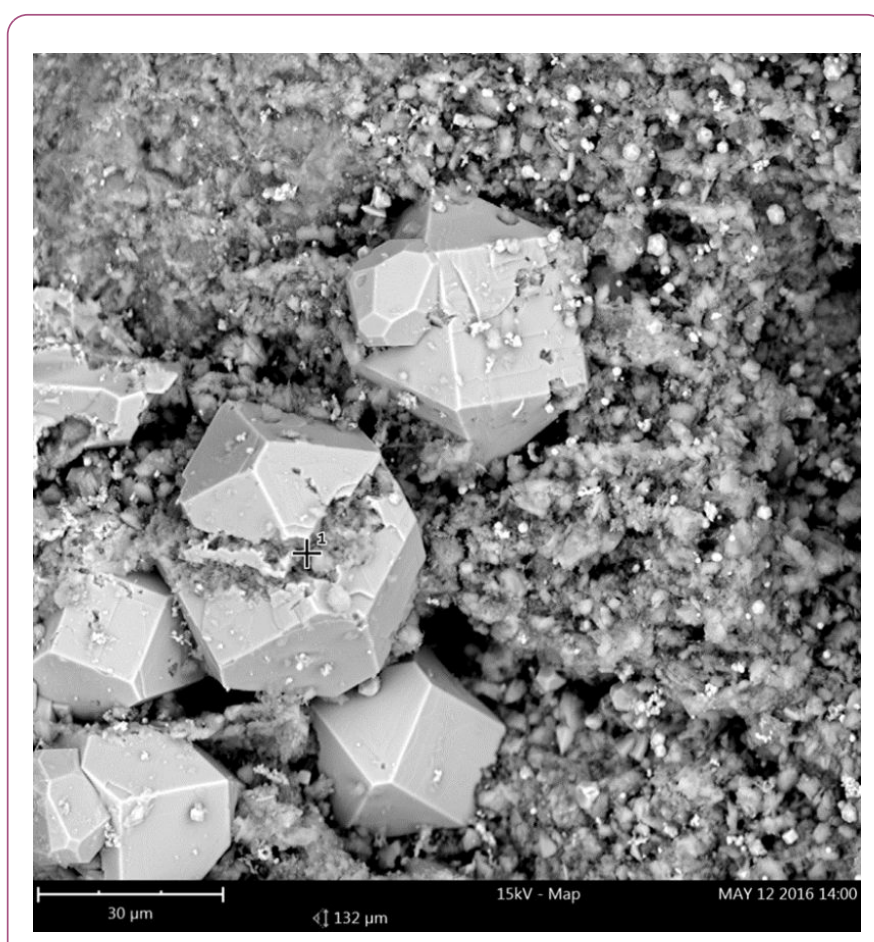

Figure 1: SEM micrograph of a crystalline $\mathrm{Mn}_{8} \mathrm{O}_{10} \mathrm{Cl}_{3}$ on the surface of the clinoptilolite (resolution given by the microscope manufacturer $\leq 14 \mathrm{~nm}$ ). 
XRD diffraction patterns showed that the sorbent was modified with a new crystalline phase, which was found to be $\mathrm{Mn}_{8} \mathrm{O}_{10} \mathrm{Cl}_{3}[11,12]$.

SEM micrograph of the crystalline $\mathrm{Mn}_{8} \mathrm{O}_{10} \mathrm{Cl}_{3}$ modification compound on the surface of the zeolite is shown in Figure 1. The sorbent is also characterized and described in more detail in another works $[11,12]$.

During the arsenic removal (sorption) experiments from water using a mixed oxidation state Mn-modified natural zeolites (clinoptilolite) a sudden unexpected precipitation was observed, in result of which translucent greyish flakes were formed and sedimented as shown in Figure 2.

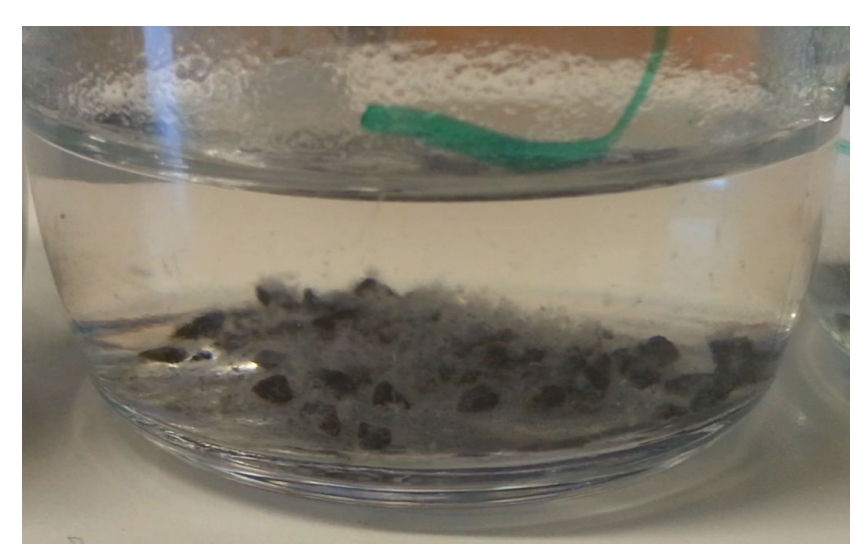

Figure 2: Greyish precipitates formed during water treatment for $\mathrm{As}(\mathrm{V})$ removal using mixed oxidation state manganese compound $\mathrm{Mn}_{8} \mathrm{O}_{10} \mathrm{Cl}_{3}$-modified clinoptilolitic zeolite.

This phenomenon has not been reported before to the best knowledge of the author. This is of significance and might have implications for the removal of arsenic compounds from water using manganese-modified sorbents. Furthermore, the quantity of formed precipitates was observed to increase with the initial concentration of $\mathrm{As}(\mathrm{V})$ present in water (from 5 to $300 \mathrm{mg} / \mathrm{L}$, studied in this work).

Limited experimental evidence indicates that precipitates are formed by interaction of $\mathrm{Mn}_{8} \mathrm{O}_{10} \mathrm{Cl}_{3}$ (mixed oxidation state $\mathrm{Mn}$ compound) and $\mathrm{As}(\mathrm{V})$, and exist in the form of hydrates, since the precipitates are unstable in air at room temperature and moderate humidity, and degrade in air fairly quickly.

While this short communication is intended only to report a novel observation, some implications can be expected. Additional studies are required to understand the underlying mechanism and implications of such precipitation during the water treatment process with Mn-modified sorbents, raising questions on limitations of the use of such sorbents.

A possible explanation is a complexation between the zeolite-modifying compound of a mixed oxidation state $\mathrm{Mn}_{8} \mathrm{O}_{10} \mathrm{Cl}_{3}$ and $\mathrm{As}(\mathrm{V})$ in water with the resulting products partially precipitating. The product is likely in a form of hydrates. This mechanism is speculated by analogy with Femodified sorbents that are often used in arsenic removal
$[11,12,16,17]$, which form inner sphere complexes. Out of 9 $\mathrm{mg}$ of $\mathrm{As}(\mathrm{V})$ that were present in the $300 \mathrm{mg} / \mathrm{L}$ initial solution, only $0.18 \mathrm{mg}$ could be uptaken by the unmodified zeolite, while the modified sorbent was able to adsorb $2.46 \mathrm{mg} \mathrm{As}(\mathrm{V})$. The difference $(2.28 \mathrm{mg})$ was likely uptaken by the modification compound $\mathrm{Mn}_{8} \mathrm{O}_{10} \mathrm{Cl}_{3}$ itself. While speculated, this difference, possibly partially, was likely involved in the complexation.

\section{Conclusion}

In this short communication, a newly observed phenomenon was reported, being an unexpected precipitation process that occured during the $\mathrm{As}(\mathrm{V})$ sorption from an aqueous solution via $\mathrm{Mn}$-modified clinoptilolite. Furthermore, with an increasing concentration of $\mathrm{As}(\mathrm{V})$ in to-be-treated water samples, the amount of formed precipitates increased proportionally. Precipitates are likely formed by interaction of $\mathrm{Mn}_{8} \mathrm{O}_{10} \mathrm{Cl}_{3}$ (mixed oxidation state $\mathrm{Mn}$ ) and $\mathrm{As}(\mathrm{V})$, possibly via complexation. The precipitates had a hydrated nature and were unstable in air even at room temperature and moderate humidity, and degraded quickly outside of water solution. The concentration of $\mathrm{As}(\mathrm{V})$ in water decreased during the arsenic removal experiment indicating that part of $A s(V)$ was sorbed and was likely involved in formation of these precipitates, which was indicated by the proportionality of quantity of formed precipitates and the initial concentration of $\mathrm{As}(\mathrm{V})$ present in water solutions. While this short communication is intended only to report a novel observation, some implications can be expected. Additional studies are required to understand the underlying mechanism and implications of such precipitation during the water treatment process, raising questions on limitations of the use of such sorbents.

\section{Acknowledgment}

Andrey is thankful for an opportunity to perform this work in the laboratory of Department of Environmental Science of Latvian University. This wouldn't be possible without prof. Maris Klavins, to whom the author is deeply grateful. Acknowledgment also goes to author's colleagues and teachers who have supported him during this work, Juris Burlakovs, Kristine Rugele and Ruta Ozola. Andrey is especially grateful to his beloved Oksana V. Golubova.

\section{References}

1. Mukherjee A, Bhattacharya P, Savage K, Foster A, Bundschuh J (2008) Distribution of geogenic arsenic in hydrologic systems: Controls and challenges. J Contam Hydrol 99: 1-7.

2. Kemper K, Minnatullah K (2005) The World Bank and the Water and Sanitation Programs of South and East Asia, Technical Report No. 31303.

3. Glocheux Y, Albadarin AB, Mangwandi C, Stewart E, Walker GM (2015) Production of porous aluminium and iron sulphated oxyhydroxides using industrial grade coagulants for optimised arsenic removal from groundwater. J Ind Eng Chem 25: 56-66.

4. A textbook of modern toxicology, 3rd edn., ed. by Hodgson E. John Wiley and Sons, Hoboken, New Jersey (2004). 
5. http://www.geog.cam.ac.uk/research/projects/arsenic/ symposium/S1.2_P_Ravenscroft.pdf

6. Bhattacharya P, Claesson M, Bundschuh J, Sracek O, Fagerberg J, et al. (2006) Distribution and mobility of arsenic in the Río Dulce alluvial aquifers in Santiago del Estero Province, Argentina. Sci Total Environ 358: 97-120.

7. Ansone-Bertina L, Klavins M (2016) Sorption of V and VI group metalloids (As, Sb, Te) on modified peat sorbents. Open Chem 14: 46-59.

8. Dupont L, Jolly G, Aplincourt M (2007)Arsenic adsorption on lignocellulosic substrate loaded with ferric ion. Environ Chem Lett 5: 125-129.

9. Figueiredo H, Quintelas C (2014) Tailored zeolites for the removal of metal oxyanions: Overcoming intrinsic limitations of zeolites. J Hazard Mater 274: 287-299.

10. Zhang FS, Itoh H (2005) Iron oxide-loaded slag for arsenic removal from aqueous system. Chemosphere 60: 319-325.

11. Krauklis AE, Ozola R, Burlakovs J, Rugele K, Kirillov K, et al. (2017) $\mathrm{FeOOH}$ and $\mathrm{Mn8010Cl3}$ Modified Zeolites for As(V) Removal in Aqueous Medium. J Chem Technol Biotechnol (Special Issue).
12. Krauklis AE (2018) Use of Synthetic and Natural Zeolites Tailored for As(V) Sorption, in Zeolites and Their Applications, ed. M. Nageeb Rashed, Intech Open.

13. Camacho LM, Parra RR, Deng S (2011)Arsenic removal from groundwater by $\mathrm{MnO2}$-modified natural clinoptilolite zeolite: Effects of $\mathrm{pH}$ and initial feed concentration. J Hazard Mater 189: 286-293.

14. http://www.vskpro-zeo.sk/en/zeolite/natural/ Slovakian natural zeolite

15. Buisson G (1976) Preparation and properties of a manganese oxychloride of formula Mn8010Cl3. J Solid State Chem 19: 175-178.

16. Lakshmipathiraj P, Narasimhan BRV, Prabhakar S, Bhaskar RG (2006) Adsorption of arsenate on synthetic goethite from aqueous solutions. J Hazard Mater 136: 281-287.

17. Guo X, Fuhua C (2005) Removal of arsenic by bead cellulose loaded with iron oxyhydroxide from groundwater. Environ Sci Technol 39: 6808-6818. 